\title{
The Widening Scope of Telemedicine in India: Delving into Its Economic Aspects and Haptic Technology
}

\author{
Shonal Rath \\ B.A Economics (Hons), University of Delhi, India.
}

\begin{abstract}
The COVID-19 pandemic has affected our nation and economy gravely, which has led to exploiting ways of setting norms for the effective distribution of healthcare advancements beyond geographical boundaries. In this paper, we propose an approach for the rapid advancement and effective distribution of healthcare in India through the enormous potential in telemedicine and haptic technology. We further address the issues in India's current healthcare infrastructure occurring due to non-availability and vacancy of doctors, social development, such as the willingness of people to invest in telemedicine by statistically analyzing bar diagrams, tabulated data, and self-assembled visual graphics. Our study shows that the potential of technology-aided approaches such as telemedicine and haptic systems in healthcare is enormous, and through effective dissemination of awareness, training, and stakeholder involvement, telemedicine and haptics could change the norms in the advancement in the healthcare system of India
\end{abstract}

KEYWORDS: Telemedicine, haptic technology, rural healthcare, infrastructure development, capacity building, marketing opportunities.
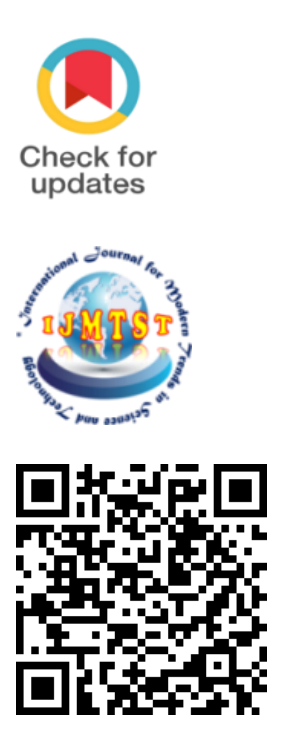

To Cite this Article:

DOI of the Article: https://doi.org/10.46501/IJMTST0706027

Available online at: http://www.ijmtst.com/vol7issue06.html

As per UGC guidelines an electronic bar code is provided to seure your paper

Shonal Rath. The Widening Scope of Telemedicine in India: Delving into Its Economic Aspects and Haptic Technology. International Journal for Modern Trends in Sceicen and Technology 2021, 7, 0706135, pp. 154-161. https://doi.org/10.46501/IJMTST0706027

Article Info.

Received: 16 May 2021; Accepted: 6 June 2021; Published: 13 June 2021 


\section{INTRODUCTION}

Health is not just the absence of malady. Individuals can create a possible future during their whole lives. In that sense, health is an advantage people have, which has its inherent worth as instrumental worth: insignificant terms, health impacts mental development, and financial growth. For instance, it decreases generations of misfortunes because of some ignoramus disease. It expands adults' profitability to enhance and ensure better performance and work output because of better nourishment. Therefore, because of this reason, the accessibility of health care services becomes a thing of utmost importance but the data points toward the contrary. According to National Health Profile-2019 (NHP-2019), India spends $1.28 \%$ of the GDP (2017-18 Budget Estimate) which is quite a low value. According to the Census of India 2011, conducted by government officials, the population's rural-urban distribution is at $68.84 \%$ and $31.16 \%$. The problem lies in the fact that the vast majority of healthcare providers in the villages 68 percent - lack formal medical education, while only 24 percent are trained AYUSH (Ayurveda, Yoga and Naturopathy, Unani, Siddha and Homeopathy) practitioners, and only $8 \%$ have an MBBS degree, according to a study led by researchers at the Delhi-based Centre for Policy Research, Georgetown University, and the University of California-San Diego covering 1,519 villages in India's 19 most populous states. This shows that much disparity prevails in the accessibility of health services in the rural areas. Adding to it, unprecedented situations like the COVID-19 pandemic make this disparity more huge. As a result, people would be more reluctant to step out of their houses for in-person health consultations, hence lowering their accessibility to healthcare facilities.

The defined outline of the study is to discuss why there is a need to adopt telemedicine on a large scale backed up by haptic technology as an efficient approach to remedy the shortage of workforce, technology and also increase the equality of the distribution of the services in terms of healthcare in India.

Here, telemedicine refers to the use of information and telecommunications technology to provide health care services to those who do not have adequate access to quality health care facilities. Whereas, Haptics refers to sensing and operating through touch, enabling the user to touch and feel the optimized virtual reality (VR) or an existing distant object, easing the medical procedures that require in-person interactions with a doctor.

\section{STRUCTURE OF PAPER}

The structure of the paper is presented in four sub-sections.

\subsection{Telemedicine as a concept}

'Telemedicine- A boon' by Pai and Jain (2020) described telemedicine incorporated with haptic technology to be the form of distant and remote diagnosis ensuring treatment of patients through telecommunications technology, thereby providing substantial healthcare to low-income regions mainly focusing on infrastructure and capacity development in the rural areas.

\subsection{Abstract development of telemedicine in India}

Ministry of Social Justice and Employment (MSJE) assigned 'National Telemedicine Task Force' 2005 that paved the way for the success of various projects like the Indian Council of Medical Research ICMRAarogyasri, internet based mobile telemedicine conglomerate.

The Ministry of Health and Family Welfare, 'Rural Statistics Report' (2019) published that telemedicine could contribute to fast-paced growth in rural health infrastructure.

\subsection{Conceptual framework around telemedicine and haptic technology}

National Institutes of Health (NIH) published 'Experiencing Growth' (2019) which says that there has only been a rough framework proposal in theory and as of no formal framework in our country about Telemedicine in India.

In the coming years, infrastructure development, production capacity are subject to technological advancement. It is only by privatising Pharma \& Health infrastructure patent, which has been proposed by the WTO as of February 2021, could bring about developments in this field of study.

\subsection{Uses of telemedicine in India}

The Ministry of Health and Family Welfare published 'Rural Statistics Report' (2019) which evaluated different types of telemedicine services like store and forward, real-time and remote or self-monitoring which provides various educational, healthcare delivery and management, disease screening and disaster 
management services all over the globe. It further proposes that telemedicine can help decrease the burden of the healthcare system to a large extent. Untied grant of $\square 25,000$ per PHC for local health action, annual maintenance grant of $\square 50,000$ per PHC and $\square 100,000$ to Rogi Kalyan Samiti (RKS) to undertake and supervise improvement and maintenance of physical infrastructure is provided.

\section{OBJECTIVES}

The COVID-19 pandemic has affected our nation and economy gravely, which has led to exploiting ways of setting norms for the effective distribution of healthcare advancements beyond geographical boundaries.

In this paper, I propose an approach for the rapid advancement and effective distribution of healthcare in India through the enormous potential in telemedicine and haptic technology. We further address the issues in India's current healthcare infrastructure occurring due to non-availability and vacancy of doctors, social development, such as the willingness of people to invest in telemedicine by statistically analyzing bar diagrams, tabulated data, and self-assembled visual graphics.

The study shows that the potential of technology-aided approaches such as telemedicine and haptic systems in healthcare is enormous, and through effective dissemination of awareness, training, and stakeholder involvement, telemedicine and haptics could change the norms in the advancement in the healthcare system of India

\section{THE PRESENT SCENARIO}

With a rise in people falling sick nowadays and the growing disease burden, the demand for healthcare services is expected to increase manifold. The recent outbreak of COVID-19 and the consequent lockdown following it, left most medical practitioners with no option but to rely on telemedicine as doctors and patients both became reluctant to participate in physical consultations. This implies that the telemedicine sector needs to be strengthened to be equipped to combat such situations. Furthermore, the geographical constraints and inadequate public transportation facilities have been a curse for rural India, even in pre-COVID times. According to the National Transport Policy Committee (NTPC), Fair Weather Roads (AWR) connected only $55 \%$ of the villages in India. Thus, it is high time that we redefine healthcare and strengthen it, especially in the rural areas, as an interdisciplinary team.

\section{STATUS OF INFRASTRUCTURE IN RURAL AREAS}

Health centres play an integral part in providing health facilities in rural India. The healthcare infrastructure in rural areas has been developed as a three-tier system. First comes the Sub-Centre, which is the grass-root level of the primary health care system in India. Next is the Primary Health Centre, the basic structural and functional unit of the public health services in developing countries, to provide accessible, affordable, and available primary health care to people. The third is the Community Health Centre which constitutes the secondary level of health care and is designed to provide referral and specialist health care to the rural population. As per the Rural Health Statistics (2019), the status of public health facilities function in the country is 1,57,411 Sub Centres (SCs), 24,855 Primary Health Centres (PHCs) and 5,335 Community Health Centres (CHCs). This is shown in Figure 1.

Figure 1: No. of health centres in rural India

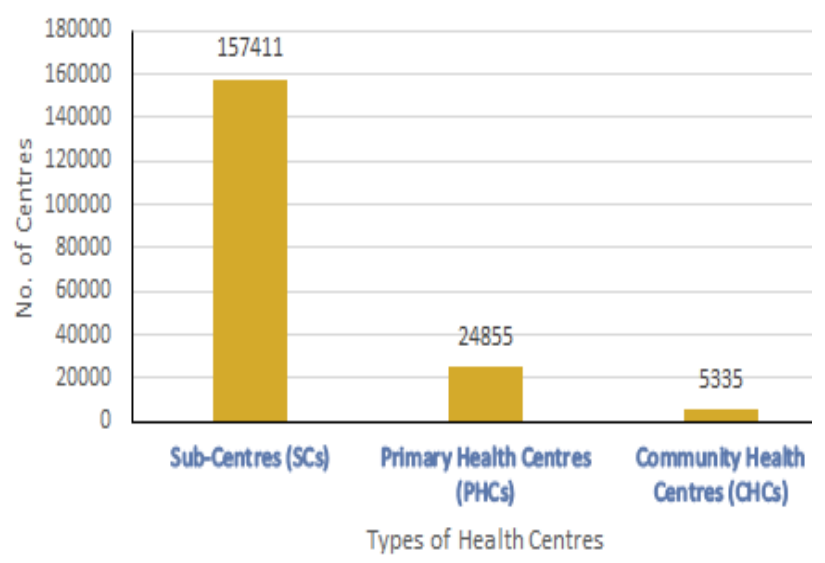

Source: Rural Health Statistics 2018-19

Now, for every healthcare centre, there is a prescribed norm of the population that it should cover. It's observed that all the centres cover more than the standard population (norm) they should cover. In other words, the average population covered per centre is more than the norm set by the government as shown in Figure 2. 
Figure 2: Average rural population covered by health centres

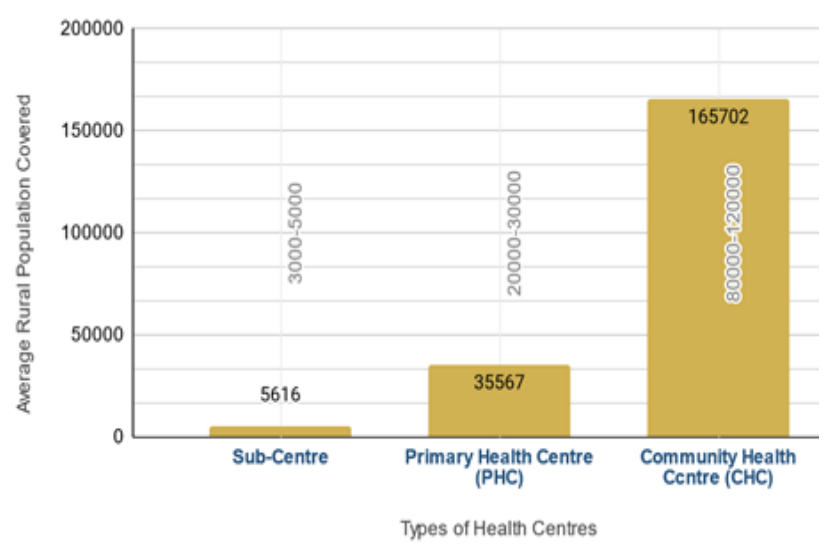

Source: Rural Health Statistics 2018-19

Sub-centers cover about 5616 of the population on average, which is more than the required norm of 3000-5000. Primary health centres cover 35,567, more than the required number of 20,000-30,000. And the average population covered by Community Health Centres is $1,65,702$, more than the necessary norm of $80,000-1,20,000$. This implies nothing but the fact that infrastructure facilities are not at par with the requirement. Also, it is observed that there is a shortfall of 43,736 SCs (23\%), 8,764 PHCs (28\%) and 2,865 CHCs (37\%) across the country as per the Rural Health Statistics (RHS) 2019 as shown in Figure 3. The figures also explain why the rural population covered under the different types of health centres in rural areas exceeds the set population norms.

Figure 3: Shortfall in health centres

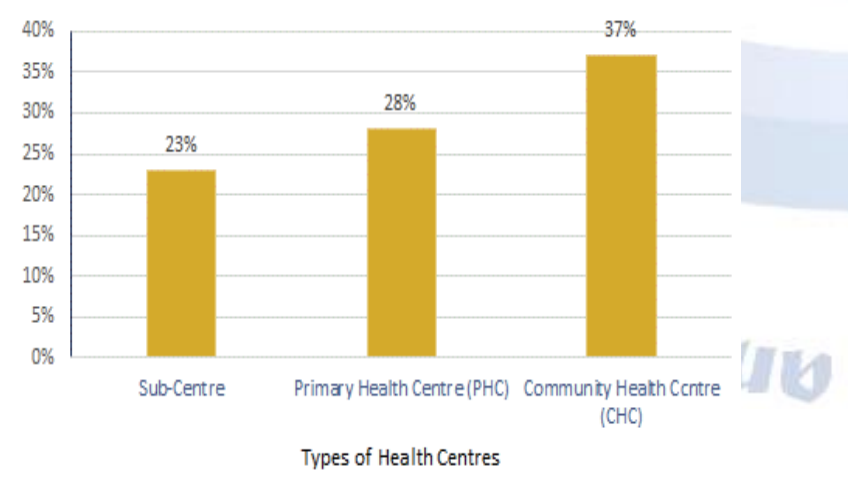

Source: Rural Health Statistics 2018-19

\subsubsection{Current status of doctors in rural India}

\section{i) Doctors reluctant to work in rural areas}

According to the Rural Health Statistics a report published by the Ministry of Health and Family Welfare (2018), 'reluctance of the doctors to contribute in the rural spaces can be attributed to the professional environment with issues like deficiency in housing conditions, infrastructure, shortage of clinical equipment and drugs, etc'. Also, Poor living and working conditions, irregular drug supply, weak infrastructure, professional isolation and the burden of administrative work--these are some of the challenges faced by doctors on rural postings, stated a 2017study by the Public Health Foundation of India.

According to the National Center for Biotechnology Information(NCBI), report on 'General Practitioners perceptions' (2019) “The doctors also feel that the financial advantages for a posting in rural areas are not quite apt to carry out household responsibilities".

Established under National Rural Health Mission (NRHM), by the Government of India (2015), AYUSH systems of medicine, an acronym for Ayurveda, Yoga and Naturopathy, Unani, Siddha and Homeopathy is a taskforce commission to provide health care delivery. We base our study of the calculation of doctors on the figures of AYUSH doctors present in PHCs and CHCs. According to the National Center for Biotechnology Information (NCBI), 'Allopathic, AYUSH and informal medical practitioners in rural India - a prescription for change,' over time, these AYUSH doctors began to be utilized as assistants to the medical officer in charge of PHCs. Later, they began to be posted as the sole in-charge of remotely located PHCs where modern medicine doctors refused to go. Hence, ensuring a good number of AYUSH doctors bridges the gap between rural people accessing healthcare facilities. We also take the parameter 'total doctors' at PHCs'.

This is because PHCs are the first point of contact to keep people well and improve their quality of life. A robust and accessible PHC system reduces pressure on hospitals by supporting people to manage their health issues in society.

Figure 4 depicts the number of doctors in rural areas. From the graph, it is observed that there exist vacant positions for doctors in Primary health centres, AYUSH doctors at Primary Health centres and AYUSH doctors at Community health centres The maximum vacancy is for PHCs with the unavailability of 7617 doctors and the minimum is for AYUSH at CHCs with the unavailability of 718 doctors. 
Figure 4: Number of doctors in rural areas

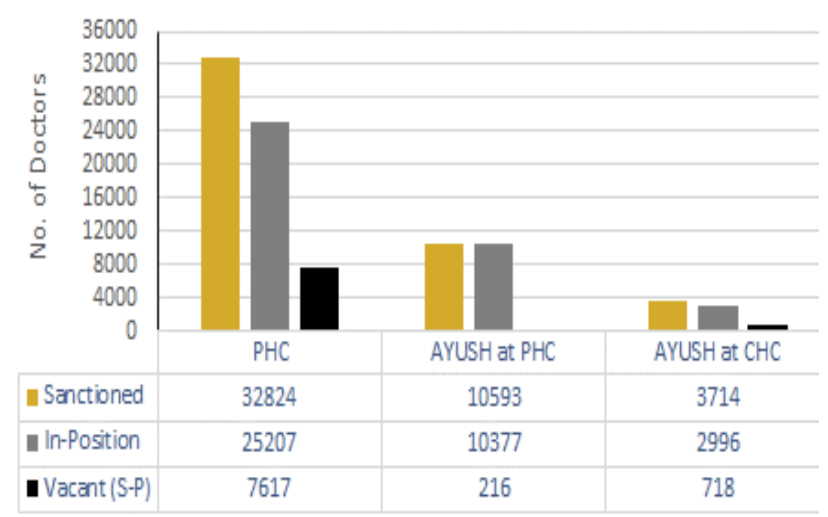

Source: Rural Health Statistics 2018-19

Note: Sanctioned (S): No. Of doctor positions opened officially by the government;

In-Position (P): No. Of doctors actually in the position; Vacant (P-S): No. Of doctors not available

\section{ii) Vacancy of doctors}

According to Rural Health Statistics (2018), the vacancy of positions of doctors in primary health care centres stands at 23.2 per cent, AYUSH doctors at primary health centres at 2.03 per cent and AYUSH at Community health centres at $19.3 \%$. This is depicted in Figure 5.

Figure 5: Vacancy of doctors

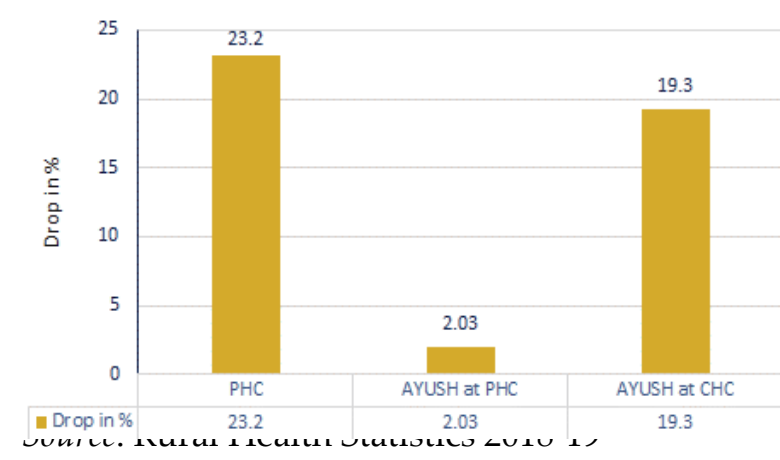

\subsubsection{Problems in urban areas due to COVID-19}

Ever since the outbreak of the COVID-19, people have been very conscious about leaving their houses, let alone human touch. Death rates tend to be higher due to complex factors, including population density, national and international connectivity, and public health responses. Hence, there was a high requirement even in the urban areas to facilitate in-person health consultations from sitting at home only.

\subsection{Telemedicine as a viable approach}

One of the possible effective ways to solve the problems mentioned above in rural and urban areas in India could be by expanding the concept of telemedicine which would ease the distribution of healthcare facilities so that the facilities may be accessible to everyone from anywhere.

Table 1 shows the SWOT Analysis of Telemedicine-

Table 1: SWOT Analysis

\begin{tabular}{ll}
\hline STRENGTH & WEAKNESS \\
\hline $\begin{array}{l}\text { Improved access to } \\
\text { healthcare by overcoming failures, risks, and } \\
\text { physical barriers. }\end{array}$ & $\begin{array}{l}\text { involved in the entire } \\
\text { procedure. }\end{array}$
\end{tabular}

The decrease in patient travel for health services thereby saving both time and money.

Excessive reliance on technology leading to the breakdown of the traditional clinician-patient relationships.

Reduces unnecessary ER Lack of professional visits that are not so calibres as well as urgent.

\section{OPPORTUNITIES}

\section{THREATS}

Acceptance of telemedicine, The reluctance of patients to by the patient as well as by use telemedicine services the surgeons. and general lack of infrastructure and resources to sustain them.

Opportunity for patients to reach out with questions, report early warning signs, and make a follow-up appointment to make sure they are on track.

\section{Improved}

timeliness of care to promote patient care quality.
Communities with low levels of literacy from text-based communication technologies such as email might get excluded.

Lack of patient follow-up making the assessment of the clinical effectiveness of 
telemedicine

services

ineffective.

Quicker and more Problems arising due to Involvement in telemedicine convenient access to the perspective of medical specialists. practitioners showing resistance to change. projects with other countries

that have better knowledge

and resources can

strengthen our healthcare
Lack of proper medicolegal protocols is also said to be keeping the physicians from embracing the telemedicine practice.

\subsubsection{Willingness to book telehealth visits}

Despite catering availability and accessibility of this technological advancement, the majority of the masses are unaware of the technicality and know-how of its operation as there were only a few cross-linked collaborations pre-COVID that justified the use of telemedicine services in India's healthcare sector.

According to the EY(Ernst \& Young) -IPA Report (2020), however, in the aftermath of COVID-19, the market for telehealth visits has witnessed an upsurge due to patients' restraint to make doctor visits in person. Figure 6 depicts the willingness to book telehealth visits.

Figure 6: Willingness to book telehealth visits

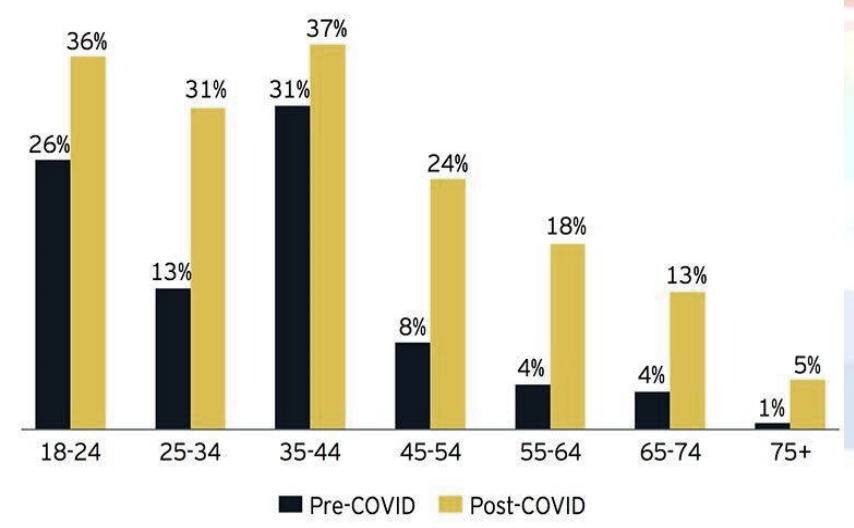

Source: EY IPA

\subsection{Laws pertaining to telemedicine in India}

No law exists in India relating to telemedicine and virtual consultation up till now. It is regulated by the combination of medical and information technology practices with their corresponding guidelines, regulations or laws. At present, the laws regulating the medical profession and information technology apply to telemedicine in India. To clarify legal issues and resolve technical issues, clear laws regulating the practice of 'telemedicine' are required. Various legislations such as The Drugs and Cosmetics Act,1940, and the Drugs and Cosmetics Codes, 1945, the Indian Medical Council Act, 1956, the Indian Medical Council (Professional Conduct, Etiquette and Ethics) Regulations, 2002, and the Clinical Establishments (Registration and Regulation) Act, 2010 (Clinical Establishments Act) are some of the laws affecting the medical profession.

Many other such as ICT include the Information Technology Act, 2000 (IT Act), the Information Technology (Intermediaries Guidelines) Rules, 2011, the Information Technology (Reasonable Security Practices and Procedures and Sensitive Personal Data or Information) Rules, 2011, Unsolicited Commercial Communications Regulations, 2007, and Telecom Commercial Communication Customer Preference Regulations, 2010 ('TCCP Regulations').

\section{THE FUTURE OF MEDICINE IN HAPTICS: A RAY OF HOPE}

Telemedicine hence has enormous prospects in making life easier for most of us by cutting down on in-person consultancies, travel costs, and making healthcare facilities readily available for the entire nation. Despite having several pros, telemedicine can't carry out the most critical healthcare facilities like surgeries, and operational treatments. In addition to the same,haptic technology comes into play to mitigate this issue and possesses unrealized capabilities to improve healthcare to a large extent. It works on the touch-feedback mechanism. It's the next step of the ladder to enhance the nation's healthcare sector after telemedicine, given that we do have the appropriate infrastructure

\subsection{Working of haptic technology in healthcare}

Haptics refers to sensing and operating through touch, enabling the user to touch and feel the optimized virtual reality (VR) or an existing distant object. Haptics also provides feedback mechanisms to those who interact with virtual or remote environments, so as to ensure a two-way flow of information. Through this technology, 
trained surgeons carry out virtual operations using haptic controls. Haptic feedback is also the key to medical interventions. For example, when a dental surgeon drills into a dental cavity or performs microsurgeries, or when an anaesthetist inserts a Tuohy needle, or when a surgeon makes a cutting. There are special devices like data gloves, joystick, etc. through which operators can receive feedback from software applications in the form of bodily sensations felt in any part of the body. The potential of haptics in the field of medical procedures and the utilization of clinical skills are great and they will affect the medical vocation at large. There is at present a lot of research going on in this particular field and is soon expected to attain its proficient state

Figure 7: Working of haptic technology

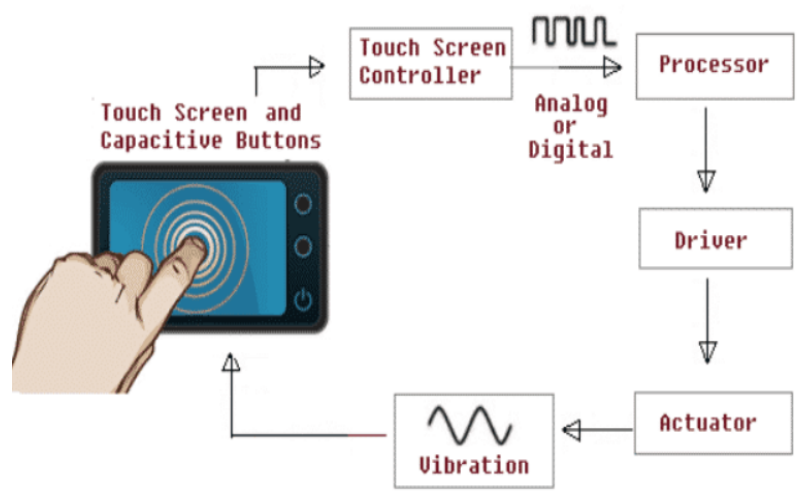

Source: Haptic technology working application

\section{DISCUSSION AND RESULTS}

From Section 3.1, it is inferred that rural infrastructure is not as per the norm set by the government. Furthermore, it is observed that doctors do not deem it fit to work in rural areas due to a variety of reasons. Therefore there lies a disparity between 'sanctioned' and 'in-position doctors' in those areas of the country.

Next, in sections 3.2.1, we also see, due to patients' aversion to making in-person doctor visits, the requirement for telehealth visits has increased due to the aftermath of COVID-19 which would give rise to broader market opportunities in the field of telemedicine. If it turns out as supposed, in no time, haptic technology would also gain a position in the market, thereby enhancing the health sector of India.
The next section, namely, 3.3, discusses how there are no laws in concept and there is a need for laws relating to telemedicine in India. Currently, only the laws regulating the medical profession and information technology apply to telemedicine in India and scope of haptic technology respectively.

The last section concludes with a brief introduction to the concept of haptic technology. It discusses how it will bring efficacy to telemedicine and its successful operation in India.

\section{CONCLUSION}

We conclude telemedicine using haptic technology would be a great and ideal approach to mitigate the shortcomings in our healthcare system of India and will take the health care sector to greater heights. Thus, a better future will need a heightened response to stimuli of touch and remote monitoring. When risen to prominence, haptic technology collaborating with other Virtual Reality will elevate the world to a whole new level of greatness. Distant intelligence has the potential to ensure urgency is taken care of by gathering clinical data from all patients simultaneously. However, some of the disadvantages being that information may be lost due to a software glitch or hardware meltdown. Therefore, relying too heavily on computer systems to prevent errors in healthcare data may be problematic. There has to be a smart balance between total dependence on computer solutions and the use of human intelligence.

\section{REFERENCES}

1. CDDEP. (2020). COVID-19 in India: State-wise Estimates of Current Hospital Beds, ICU Beds, and Ventilators. Center for Disease Dynamics, Economics \& Policy, pp 189-234. Retrieved from https://cddep.org/publications/covid-19-in-india-tate-wis e-estimates-of-current-hospital-beds-icu-beds-and-ventila tors/

2. Chandra, S., \& Patwardhan, K. (2018). Allopathic, AYUSH and informal medical practitioners in rural India - a prescription for change. Journal of Ayurveda and integrative medicine, 9(2), https://doi.org/10.1016/j.jaim.2018.05.001

3. EY-IPA. (2020). Healthcare goes mobile: Evolution of teleconsultation and e-pharmacy in the new Normal. Ernst \& Young - Indian Pharmaceutical Alliance. Retrieved from

https://assets.ey.com/content/dam/ey-sites/ey-com/en_in/ 
topics/health/2020/09/healthcare-goes-mobile-evolution-o f-teleconsultation-and-e-pharmacy-in-new-normal.pdf

4. FutureBridge (2020). Haptic - Adding a New Dimension to Virtual Reality. FutureBridge, Retrieved.from.https://www.futurebridge.com/industry/ perspectives-mobility/haptic-adding-a-new-dimension-to -virtual-reality/

5. Howdle, D. (2019). Worldwide Mobile Data Pricing League: Cost of 1GB in 230 countries. Cable.co.uk Research News, $\quad$ p.p 10-18. Retrieved fromhttps://www.cable.co.uk/mobiles/worldwide-data-p ricing/

6. India Haptics Technology Market. (2019). Industry: Analysis, Trends, Forecast, Overview, Research, Opportunity, Growth and Potential. Retrieved.from.https://www.mordorintelligence.com/ind ustry-reports/opportunities-in-haptics-technology-in-indi a

7. Khan, F., Chaudhary, F., \& Yousaf, M. N. (2017). Role of Telemedicine in Developed and Under-Developed Countries. IEEE Internet Initiative. Retrieved.from.https://internetinitiative.ieee.org/newslett er/may-2017/role-of-telemedicine-in-developed-and-und er

developedcountries\#:\%7E:text=Telemedicine\%20depends \%20on\%20various \%20factors,substandard\%20manageme nt\%2C\%20and\%20conflicting\%20policies

8. Ministry of Home Affairs Publications. (2018). Rural Health Statistics 2018-19, 50-59. India.

9. Naikawadi, A., Harry, A., \& Shaifal. (2020) Teleconsultation marked its growth in the healthcare industry during COVID-19, Times of India Blog, 12-17. Retrieved from https://timesofindia.indiatimes.com/blogs/voices/telecons ultation-marked-its-growth-in-the-healthcare-industry-d uring-covid-19/

10. Pai. V., \& Jain, A. (2020). Telemedicine - Recent Developments in India. Lexology. Retrieved from https://www.lexology.com/library/detail.aspx?g=f1f94dc9 -295c-47c1-81f5-1d4e761b82c1

11. Planning Commission of India P.C.I. (2017). Strategy Committee. Delhi. India

12. PRS India (2020). Analysis: Health and Family Welfare. Demand for Grants 2020-21, 1-6. Retrieved.from.https://www.prsindia.org/parliamenttrac $\mathrm{k} /$ budgets/demand-grants-2020-21-analysis-health-and-fa mily-welfare

13. PubMed Central (PMC) (2016). Telemedicine in Rural India, 65-78. New Delhi. India

14. PubMed Central. (2018). Telemedicine in Rural India. $\mathrm{p}$ 65-92. New Delhi. India
15. Raman, D. J. A. D. (2020, June 23).COVID-19 Crisis: Ventilators Are Important - but They're Not Perfect. The Wire Science, pp 435-476.

Retrieved.from.https://science.thewire.in/health/coronavi rus-covid-19-ards-ventilators-vili-icu-high-flow-nasal-the cannula/

16. Ramaswamy, N. (1998). Rural transport in India. Current Science,75(8), 800-803. Retrieved April 7, 2021, from http://www.jstor.org/stable/24101627

17. Salman, A. (2019).Haptic Technology: Feedback, Devices, Working Principle, Applications. Electrical Funda Blog. Retrieved from https:/electricalfundablog.com/haptic-technology/

18. Sarin, R. (2020, July 11). As COVID-19 curve rises, surge in ventilators causes glut. The Indian Express, 76-89. Retrieved from https://indianexpress.com/article/india/as-covid-curve-ris es-surge-in-ventilators-causes-glut-6495017/

19. T.M.R. (2020). The Market Records, 12-25. Retrieved.from.https://hemarketrecords.com/2020/09/26/ haptic-technology-market-size-trends-analysis-demand-o utlook-and-forecast-2027-immersion-precision-microdriv es-limited-ultrahaptics

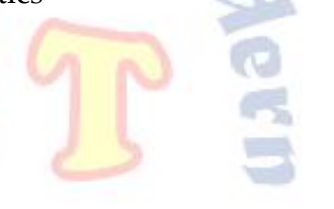

